\title{
Hubungan Faktor Stressor Internal Ibu Primigravida dalam Menghadapi Persalinan
}

\author{
Dara Ardhia, Mariatul Kiftia, Mira Rizkia, Nevi Hasrati Nizami, Elka Halifah \\ Universitas Syiah Kuala, Fakultas Keperawatan, Jl. Teuku Nyak Arief No.441, \\ Kopelma Darussalam, Kec. Syiah Kuala, Kota Banda Aceh, Aceh \\ Email:daraardhia@unsyiah.ac.id
}

$\begin{array}{ll}\text { Diterima } & : \text { 13 November } 2020 \\ \text { Disetujui } & : \text { 30 November } 2020 \\ \text { Dipublikasikan } & : \text { 10 Desember } 2020\end{array}$

\begin{abstract}
Abstrak
Latar Belakang dan Tujuan: Persalinan merupakan suatu proses pengeluaran janin, plasenta dan jaringan lainnya dari dalam rahim melewati jalan lahir baik secara pervaginam maupun section caesaria. Proses ini menyebabkan perubahan baik secara fisik dan psikologis, salah satu perubahan yang terjadi pada psikologis yaitu kecemasan dan ketakutan terutama pada ibu primigravida. Tujuan dari penelitian ini adalah untuk mengetahui hubungan stressor internal dengan aspek psikologis ibu primigravida dalam menghadapi persalinan di Puskesmas Mutiara Barat Pidie.

Metode: Metode analitik dengan pendekatan crosssectional. Populasi dalam penelitian ini adalah seluruh ibu primigravida di Puskesmas Mutiara Barat Pidie yang berjumlah 56 responden, adapun tehnik pengambilan sampel dalam penelitian ini dengan tehnik simple random sampling.

Hasil: Hasil uji statistik dengan chi-square didapatkan P-value 0,022 $\leq 0,05$ menunjukkan bahwa ibu dengan stress internal ringan secara psikologis siap menghadapi persalinan yaitu sebanyak $(80,0 \%)$.

Simpulan dan Implikasi: Ada hubungan antara stressor internal dengan psikologis ibu primigravida dalam menghadapi persalinan. Petugas kesehatan atau bidan untuk lebih meningkatkan konseling dan penyuluhan mengenai kesiapan psikologis ibu agar dapat menurunkan tingkat kecemasan ibu untuk menghadapi proses persalinan.
\end{abstract}

Kata Kunci : Persalinan; Primigravida; Psikologis

Sitasi: Ardhia D, Kiftia M, Rizkia M, Nizami N H \& Halifah E. (2020). Hubungan faktor stressor internal ibu primigravida dalam menghadapi persalinan. The Indonesian Journal of Health Science. 12(2), 193198

Copyright: () 2020 Ardhia et. al. This is an open-access article distributed under the terms of the Creative Commons Attribution-NonCommercial 4.0 International License, which permits unrestricted use, distribution, and reproduction in any medium, provided the original author and source are credited.

Diterbitkan Oleh: Universitas Muhammadiyah Jember

ISSN (Print): 2087-5053

ISSN (Online): 2476-9614 


\begin{abstract}
Background and Aim: A primigravida will feel anxiety, fear, and lack of confidence commonly because they do not have experience from the beginning of pregnancy to delivery so that any physical and psychological changes that cause of various psychological problems. The purpose of this research was to find out the influence factors of primigravida psychologist mothers to give birth facing at Mutiara Barat Health Center of Mutiara in Pidie, Aceh 2019.

Methods: The type of this research was analytic through crossectional design. The population in this research was all of primigravida mother at Mutiara Barat Health Center in Mutiara that consisted of 126 people that data found January up to December in 2018. A number of 56 respondents were taken as samples by using simple random sampling through slovin formulas.

Results: The result of the research showed that (80.0\%) sufficient internal stressor to primigravida psychologist mothers to give birth facing through statistical test result by Chi Square obtained P-value 0,022 < 0,05.

Conclusion: There was relationship between internal stressor to primigravida psychologist mothers to facing birth at Mutiara Barat Health Center. Therefore, this research should be additional information and knowledge to health worker and midwife to increase their counseling about primigravida psychologist mothers to give birth facing and decrease anxiety levels.
\end{abstract}

Keywords: Giving Birth; Primigravida; Psychologist

\section{PENDAHULUAN}

Persalinan merupakan sebuah proses pengeluaran hasil konsepsi yang mampu hidup dari dalam uterus ke dunia luar. Melahirkan dan persalinan normal adalah proses pengeluaran janin. Terjadi pada jangka penuh (37-42 minggu) dan lahir secara alami. Kepala dan punggung berlangsung selama 18 jam. Tidak ada komplikasi pada janin (Jannah, 2015).

Proses persalinan dipengaruhi oleh beberapa faktor, baik dari fisiologis maupun psikologis. Faktor fisiologis meliputi faktor power, passanger, passage sedangkan factor psikologis atau psyche juga sangat berperan pada saat persalinan. Faktor psyche yang di sebutkan merupakan factor kecemasan sering terjadi ketika akan memasuki persalinan. Dampak buruk dari kecemasan ibu hamil adalah memicu terjadinya rangsangan kontraksi.

Wanita hamil di beberapa negara berkembang di dunia memiliki risiko penyakit jiwa yang lebih tinggi, antara lain Ethiopia, Nigeria, Senegal, Afrika Selatan, Uganda dan Zimbabwe, yaitu masing-masing $15,6 \%$ dan 19,8\% ibu postpartum (WHO, 2013a).Di Uganda, sebanyak 18,2\% ibu di Nigeria mengalami depresi atau kecemasan sekitar 125\%, 19\% di Zimbabwe, dan $41 \%$ di Afrika Selatan(WHO, 2013b). Selain itu, $81 \%$ Inggris Raya mengalami masalah psikologis. Dalam kehamilan. Di Prancis, sebanyak $7,9 \%$ primipara merasa cemas selama kehamilan, $11,8 \%$ merasa tertekan selama kehamilan, dan $13,2 \%$ wanita mengalami kecemasan dan depresi (Ibanez, 2015). 


\section{METODE PENELITIAN}

Metode

penelitian menggunakan analitik dengan pendekatan cross sectional. Sampel dalam penelitian ini adalah ibu primigravida di Puskesmas Mutiara Barat Pidie yang berjumlah 56 responden, adapun tehnik pengambilan sampel dalam penelitian ini dengan tehnik simple random sampling. Analisis data menggunakan uji chi square dengan komputer program SPSS.

\section{HASIL}

Karakteristik responden dalam penelitian ini diketahui bahwa sebagian besar usia ibu primigravida berusia 21 - 25 tahun sebanyak 35 orang $(62,5 \%)$, pekerjaan mayoritas sebagai ibu rumah tangga sebanyak 39 orang $(69,6 \%)$ (Tabel 1).
Tabel 2 menunjukkan kondisi psikologis ibu primigravida. Diketahui bahwa sebagian besar distribusi ibu primigravida memiliki aspek psikologis yang siap menghadapi persalinan dengan frekuensi $71,4 \%$. Sedangkan pada tingkat stressor diketahui bahwa sebagian besar ibu primigravida memiliki stressor ringan sebanyak 53,6\% (Tabel 3).

Tabel 4 menunjukkan bahwa $80 \%$ ibu primigravida dengan stressor ringan secara psikologis siap untuk menghadapi persalinan, hal ini terlihat dari hasil uji statistika diperoleh nilai $P$ yaitu 0,0022 sehingga nilai $\mathrm{p} \leq \alpha \quad 0,05$, Maka dapat disimpulkan bahwa terdapat hubungan stressor internal dengan psikologis ibu primigravida.

Tabel 1. Distribusi Frekuensi Usia Responden $(n=56)$

\begin{tabular}{lcc}
\hline Karakteristik & F & $\%$ \\
\hline Usia & 35 & 62,5 \\
21 - 25 Tahun & 17 & 30,4 \\
26-30 Tahun & 4 & 7,1 \\
31 -32 Tahun & & \\
Pekerjaan & 39 & 69,6 \\
IRT & 8 & 14,3 \\
Honorer & 2 & 3,6 \\
PNS & 7 & 12,5 \\
Lainnya & 56 & 100 \\
\hline Total & &
\end{tabular}

Tabel 2. Distribusi Frekuensi Psikologis Ibu Primigravida

\begin{tabular}{lcc}
\hline \multicolumn{1}{c}{ Psikologis Ibu Primigravida } & F & \% \\
\hline Siap & 40 & 71,4 \\
Tidak Siap & 16 & 28,6 \\
\hline Total & 56 & 100 \\
\hline
\end{tabular}

Tabel 3. Distribusi Frekuensi Frekuensi Stressor Internal

\begin{tabular}{lcc}
\hline Stressos Internal & F & \% \\
\hline Ringan & 30 & 53,6 \\
Sedang & 26 & 46,4 \\
\hline Total & 56 & 100 \\
\hline
\end{tabular}


Tabel 4. Hubungan Stressor Internal terhadap Psikologis Ibu Primigravida

\begin{tabular}{|c|c|c|c|c|c|c|c|}
\hline \multirow[t]{3}{*}{$\begin{array}{l}\text { Stressor } \\
\text { Internal }\end{array}$} & \multicolumn{4}{|c|}{$\begin{array}{l}\text { Psikologis Ibu } \\
\text { Primigravida }\end{array}$} & \multicolumn{2}{|c|}{ Jumlah } & \multirow{2}{*}{$\begin{array}{c}\text { P Value } \\
0.022\end{array}$} \\
\hline & \multicolumn{2}{|c|}{ Siap } & \multicolumn{2}{|c|}{ Tidak Siap } & \multirow[t]{2}{*}{$\mathrm{F}$} & \multirow[t]{2}{*}{$\%$} & \\
\hline & $\mathrm{F}$ & $\%$ & $\mathrm{~F}$ & $\%$ & & & \\
\hline Ringan & 24 & 80,0 & 6 & 20,0 & 30 & 100 & \\
\hline Sedang & 16 & 61,5 & 10 & 38,5 & 26 & 100 & \\
\hline Jumlah & 40 & 71,4 & 16 & 28,6 & 56 & 100 & \\
\hline
\end{tabular}

\section{PEMBAHASAN}

Berdasarkan hasil dapat diketahui terdapat hubungan yang signifikansinya tinggi antara stressor internal ibu hamil primigravida dalam menghadapi persalinan, hal ini sesuai dengan konsep (Asrinah, 2010) yang menjelaskan bahwa faktor stressor internal pada ibu yaitu faktor-factor yang dapat menjadi pemicu stress yang bersumber dari dalam diri ibu hamil tersebut, seperti cemas, tegang ketakutan, sakit, cacat, kurang percaya diri, perubahan peran menjadi orang tua, sikap ibu hamil terhadap kehamilannya, takut pada kehamilan dan takut menhadapi persalinan. Sumber tekanan internal ini lebih banyak bersumber dari dalam diri ibu hamil primigravida. Beban psikologis yang dirasakan oleh ibu dapat mencetuskan gangguan perkembangan pada bayi saat dilahirkan dan salah satu tekanan internal yang sering dihadapi ibu adalah kecemasan.

Kecemasan adalah suatu perasaan yang mengkhawatirkan, merasa gugup, merasa gelisah terhadap sesuatu dengan hasil yang tidak pasti dan dapat terjadi beriiringan, mempengaruhi, atau dapat menyebabkan depresi (Kajdy, 2020). Penelitian sebelumnya telah menunjukkan bahwasanya kecemasan merupakan sebuah emosi negatif yang sering terjadi pada masa kehamilan, terutama di trimester tiga kehamilan (Silva, 2017).

Maka dapat diketahui kecemasan itu terjadi pada masa perinatal sampai dengan masa pasca persalinan dan pospartum, Hal ini seperti hasil penelitian yang telah dilakukan Brown and Lumley, 2000; Ross and McLean, 2006 ; Lee et al, (2007) bahwa masa perinatal yang dimulai dari kehamilan pertama sampai masa post partum terjadi peningkatan risiko depresi dan kecemasan hal ini di karenakan adanya perubahan social, psikologis dan fisik yang terkait dengan kehamilan dan persalinan ibu. Sedangkan menurut pendapat (Aprilia, 2011) menyebutkan bahwa pada ibu primigravida salah satu penyebab terjadinya kecemasan karena proses persalinan dianggap sebagai peristiwa yang menyeramkan, menyakitkan, dan paling menegangkan dibandingkan dengan peristiwa apapun dalam kehidupan seorang perempuan.

Hal ini berbeda sebaliknya yang ditemukan oleh penelitian (Astria, 2009) yang menjelaskan bahwa dari 150 ibu hamil yang menjadi responden, jumlah ibu hamil yang mengalami rasa cemas nyatanya lebih tinggi dialami oleh kelompok ibu dengan kehamilan pertama (primigravida), yaitu 66,2\% dibandingkan dengan kelompok ibu hamil dengan anak lebih dari satu 
(multigravida) yang mengalami rasa cemas yaitu sebanyak 42,2\%. Hal ini sejalan dengan penelitian (Durankuş, 2020) yang menjelaskan bahwa gangguan psikologis selama kehamilan dalam sumber literatur yang ada telah dihubungkan dengan berbagai masalah komplikasi misalnya kelahiran prematur, berat badan lahir rendah (BBLR), pertumbuhan janin terganggu serta komplikasi pasca persalinan. Selain itu di jelaskan bahwa gangguan psikologis ini juga dikaitkan dengan terjadinya hipertensi pada kehamilan, preeklampsia, serta diabetes gestasional (diabetes yang terjadi pada kehamilan).

Penelitian ini didapatkan bahwa faktor psyche dengan ibu yang memiliki stressor ringan dan siap menghadapi persalinan sebanyak 80\% ibu hamil, hal ini menunjukkan ibu hamil dengan primigravida yang berada di wilayah Pidie siap menghadapi persalinan, hal ini disebabkan karena sumber informasi yang didapat dari tenaga kesehatan juga mudah, serta patuhnya ibu hamil primigravida terhadap kunjungan kehamilan ke pelayanan kesehatan, selain itu seringnya pertemuan antara ibu hamil baik adanya kelompok prenatal maupun kelompok konseling sehingga ibu primigravida sering berbagi sumber informasi yang didapat kepada ibu primigravida lainnya.

Salah satu alternatif lainnya dalam mengurangi tingkat kecemasan perempuan dengan kehamilan pertama atau ibu primigravida adalah dengan melakukan konseling kelompok prapersalinan. Konseling pra persalinan ini merupakan upaya untuk memberikan bantuan untuk memberi solusi pada masalah (ibu hamil) yang terjadi selama kehamilan melalui wawancara konseling secara kontinu yang dilakukan di trimester ketiga. Konseling prapersalinan ini sama dengan hasil penelitian yang dilakukan (Trias Novitasari, 2013) yaitu adanya perubahan tingkat kecemasan pada ibu hamil yang cukup berpengaruh antara pre test dan juga post test pada kelompok percobaan dengan kelompok kontrol dengan nilai gaint score -3,155. Maka dapat diberi kesimpulan bahwa untuk mengurangi tingkat kecemasan ibu hamil dengan primigravida dapat diberikan terapi konseling kelompok dan juga dapat dibentuk kelompok prenatal.

\section{SIMPULAN}

Ada hubungan yang signifikan antara stressor internal dengan kesiapan ibu hamil dengan primigravida dalam menghadapi persalinan. Semakin ringan stressor internal yang dialami ibu maka semakin siap pula psikologis ibu dalam menghadapi persalinan.

\section{SARAN}

Perlu adanya screening awal dari masa awal kehamilan untuk mencegah peningkatan stressor internal ibu hamil terutama ibu dengan primigravida dalam menghadapi persalinan. Bagi tenaga kesehatan di butuhkannya informasi yang detail dan akurat terkait kehamilan dan persalinan sehingga stressor intal pada ibu hamil dapat diatasi.

\section{DAFTAR PUSTAKA}

Aprilia, Y. d. (2011). Gentle birth. Jakarta : PT Gramedia Widiasarana. 
Asrinah, S. D. (2010). Asuhan kebidanan masa kehamilan. Yogyakarta: Graha Ilmu.

Astria, Y. (2009). Hubungan karakteristik ibu. Fakultas psikologi , Universitas Islam Negeri Jakarta

Dr Louise Phillips, P. R. (2015). The first antenatal appointment: An exploratory study. Midwifery, 31, 756-764.

Durankuş, F. \&. ((2020).). Effects of the COVID-19. Journal of Maternal-Fetal and .

Ibanez, G. e. (2015, Mei 31 ). Effects of antenatal maternal deprision and anxiety on dari children's earlycognitive development: A prospective cohort study. Plos One. Vol. 10, No 8, August 2015, DOI: 10.1371/Journal.Pone.013584 9.

Jannah N. (2015). Buku ajar asuhan kebidanan kehamilan. Yogyakarta : CV Andi Offset.

Kajdy, A. F. (2020). Risk factors. 17.

Silva, M. M. ((2017).). Anxiety in pregnancy:. Journal of School of Nursing , 51, 1-8.

Trias Novitasari, d. (2013). Kefektivan konseling kelompok pra persalinan untuk menurunkan tingkat ecemasan primigravida menghadapi persalinan. Developmental and Clinical Psychology , 62 - 66.

WHO. (2013). Interventions for common perinatal mental disorder in women in lowand middle-income countries: A Systematic review and meta-analysis.

WHO. (2013). Maternal mental health and child health and development in low and middle income countries. Geneva, Switzerland.

WHO. (2013). Maternal mental health and child health and development in low and middle income countries. Geneva, Switzerland. 